\title{
Stylistics, Literary Criticism, Linguistics and Discourse Analysis
}

\author{
Saleh Ahmed Saif Abdulmughni ${ }^{1}$ \\ ${ }^{1}$ Department of English and Literature, College of Arts and Science, Wadi-Ad-Dawasir, Prince Sattam bin \\ Abdul-Aziz University, Saudi Arabia \\ Correspondence: Saleh Ahmed Saif Abdulmughni, Prince Sattam bin Abdul-Aziz University, P. O. Box 54, \\ Riyadh 11991, Saudi Arabia. E-mail: salehsaif55@yahoo.com
}

Received: October 16, $2018 \quad$ Accepted: March 2, $2019 \quad$ Online Published: March 7, 2019
$\begin{aligned} & \text { doi:10.5539/ijel.v9n2p412 } \\ & \text { URL: https://doi.org/10.5539/ijel.v9n2p412 }\end{aligned}$

\begin{abstract}
There is confusion regarding the differences between linguistics, stylistics, literary criticism, and discourse analysis (DA) among teachers and learners of the English Major due to their overlapping natures, blurred boundaries, and analysis approaches. Therefore, the present study examines the similarities and differences of these four fields to make a clear demarcation between them. A descriptive and comparative approach using exemplary text was used in the study and the stylistics were thoroughly investigated, analyzed and exemplified in small-scale (one phrase, clause or sentence) or wider-scale (a paragraph). Finally, value judgments on the importance and value of the stylistics were furnished. This research enhances the prospects of pedagogical studies of different language learning and teaching of these four fields. This has opened the window for teacher-oriented studies and presented valid and genuine analytical and diagnostic studies of the related issues to enhance the accessibility of a clear distinction of the above stated fields.
\end{abstract}

Keywords: linguistics, stylistics, literary criticism, discourse analysis, theories

\section{Introduction}

There are four primary disciplines are of interest including; linguistic analysis, literary criticism, discourse analysis, and stylistics analysis with respect to literature analysis. Of these, the latter two are comparatively new sciences and are used interchangeably by educators when teaching stylistics. Stylistics is applied to areas such as discourse analysis and literary criticism. However, there is a lack of clear understanding of the nature and study of these four disciplines, as seen in teachers' presentation of classical criticism, bibliographical criticism and practical criticism as a single course of stylistics. A primary reason for this is owed to their inability to distinguish between these disciplines or approach a text analysis stylistically. Since biographical and practical criticism focuses on abstract emotions and justification that have no physical grounds in the literary text, they do not play a direct role in the analysis of literary texts. For this reason, bibliographical critics require extensive experience and sensitivity. In particular, stylistician`s require an extensive knowledge of language to explore how literary texts work, and the impact of language in creating and transforming a literary text.

Style is the manner of linguistic expression in prose or verse. It is how a speaker or writer says whatever he says. It refers to the way in which language is used in a given context by a specific writer of speaker for a specific person. The teachers fail to effectively teach stylistics, because it draws from linguistics, psychology and literary criticism, since a majority of them are well-versed in linguistics, applied linguistics, literature or teaching methodology. Therefore, they either teach grammatical analysis or literary criticism when teaching stylistics. Teachers should have a complete understanding of both linguistics and literature since literature is composed of language.

\subsection{Novelty of the Study}

The modern structural linguistics along with the generative linguistics are helpful in learning and teaching the foreign languages, as far as education is concerned. Moreover, linguistics is likely to help in shielding the disciplines against a fierce resistance towards invasion. The linguistics have the right of analyzing literary texts. The linguistics attempt to violate the relevant and autonomy of literary criticism, as discipline has its own right. Therefore, the aim of this article was to discuss the relationships among linguistic analysis, literary criticism, discourse analysis, and stylistics analysis, with a special focus on demonstrating the differences between linguistics, stylistics, and literary criticism. It additionally aims to demonstrate the usage of language in literary 
texts by relating it to its artistic function.

\section{Literature Review}

According to Halliday, Michael and Jonathan Webster (2006), linguistics is the scientific study of human language as a system of human communication. It encompasses different areas of investigation such as phonetics (articulation, transmission and reception of speech sounds), phonology (system and patterns of sounds in language), morphology (word formations), syntax (sentence structure), semantics (meaning) and the like.

Aslam et al. (2014), defined stylistics as a discipline of applied linguistics, which was primarily involved in evaluating the styles of textual content. In this context, stylistics aimed to interpret textual content, rather than simply describing the text's formal characteristics. Additionally, the study discussed that stylistics was a mean to evaluate the impact of linguistics on literary effects. Current trends in stylistics have resulted in the development of sub-disciplines in the form of feminist stylistics (Montoro, 2014), cognitive stylistics (Burke, 2015, pp. 75-93) and discourse stylistics (Naciscione, 2017); these are all sustained by insight from feminist theory, cognitive theory and discourse theory respectively. Stylistics is therefore an important component of pedagogical methods in the teaching and learning of language.

In fact, a strong difference was highlighted between stylistics and literary criticism, in that the latter predominantly focused on interpreting the textual content itself, rather than the styles as seen in stylistics analysis. Furthermore, discourse analysis (DA) was defined by Gee (2004) as being a study of how written and spoken language stands as a representation of socio-cultural identities and perspectives. In fact, DA is a general term for a number of approaches to analyze written, vocal, or sign language use, or any significant semiotic event (Hult, 2017). DA was identified as a supplement or even a replacement of text in post-structuralism. Of recent significance is the term 'critical discourse analysis', as popularized through Fairclough's 'Language and Power' (2001). Specifically, this is a type of discourse analysis that emphasizes how socio-political written and spoken language serves as an enaction of social inequality and power abuse (Van Dijk, 2015).

\subsection{The Subject Matter of Linguistics}

The study of language is from either a diachronic perspective or synchronic, with each method having its own significance (Colleman, Röthlisberger \& Zehentner, 2017). A diachronic study compares the characteristics of two languages or more throughout the evolution of time at different lexical, phonological, morphological, syntactic, and semantic levels. A synchronic study contrasts the characteristics of two languages at different points in history for didactic purposes; while, the diachronic study is comparative.

The present study is contrastive; it represents part of the Structuralists' approach to language teaching. It is based on the assumption that contrasting the mother tongue with the target language will enable syllabus designers, teachers and learners to know the similarities and differences between two languages. Consequently, they may focus on the differences that create issues for language learners. This was the best way to teach a language in the heyday of structural linguistics and patterns of language teaching. The distinctive communicative aspects of species are determined from the linguistics studies, where stylistics defines the difference in style or language by relying on the condition in which the language is utilized and further on influence the speaker or writer to construct on the listener or reader. It implements concepts and techniques of modern linguistics to the literature aspects. It mostly leads to the written language study such as literary texts; although, stylistics often entails spoken language analysis. The selections available are concerned with stylistics to a writer and the causes why specific expressions and forms are utilized as compared to others.

The present study has focused on the relation between language and artistic function to connect the critics' concern of aesthetic appreciation with the linguist's concern of linguistic description. Leech and Short (2007) highlighted that two faculties are brought simultaneously to the literary text; namely, the ability to respond to the text as a literary work and the ability to observe its language. This has been quoted as follows:

"There is a circular movement whereas literary insight is modified or simulated for linguistic observation and where linguistic observation is further stimulated by literary insight. This movement is usually formulated based on the theory and theory testing, which implies scientific method."

\subsection{Meanings of Stylistics in Different Contexts}

Style can be applied to both oral and written forms of literary or non-literary varieties of a language and refers to a variation in a person's speech or writing. Style often differs from casual to formal being discussed, considering the type of situation, the location, historical context, the topic, the person or persons addressed. A specific style is usually denoted to as a stylistic register or variety such as colloquial or formal. The same interests or occupation is often shared by speech variety that is utilized by a specific cluster of individuals. A specific register usually 
differs itself from other registers by possessing assorted different words or by utilizing phrases or words in a specific approach and occasionally by specific legal language or grammatical constructions.

\subsubsection{Style Shift}

Style shift refers to style changes during verbal or written communication. Conventionally, style shifts occur when the writer or speaker reassesses or redefines a particular situation. For example, a writer may add informal details in a formal text because he may be on familiar terms with the addressee. Furthermore, the speaker shifts to informal speech to lessen the tense situation in highly formal political speech. This is further seen in interviews, where interviewees are encouraged to relax; consequently, they shift from formal style to informal, thereby setting off their expressivity.

\subsubsection{Style Variability}

The stylistic variation of an individual or group can be measured by analyzing recorded speech or written text and making comparisons among them. Different words or expressions or different sentence structures are observed from the stylistic variations that can be adhered in different speech sounds. For instance, individuals tend to say different words based on the informal style in English pronunciation. Possibly, their style varies as per the degree of formality when expressing themselves in words. An example is highlighted:

More formal: (1) I wonder if you could possibly be kind enough to condescend to give me your pen? (2) We were somewhat dismayed by her lack of response to our invitation.

Less formal: (1) Could I have your pen, please? (2) We were rather fed up that she didn't answer when we invited her.

Informal: Give me your pen, please.

Stylistics analysis differs from linguistic analysis as the linguistics analyzes the word structures, phrase structures, clause structures, and sentence structures, which are bases for stylistic text analysis. Stylistic is an approach of textual interpretation in which pre-eminence of place is designated to language. Linguistic structures are essential guide of the text function that comprise assorted forms, levels, and patterns based on language stylistics. Textual language emphasizes the foreground stylistics from other types of critical practice. According to (Crystal \& Davy, 2016; Wales, 2001), assorted theories or meanings of stylistics are present in linguistic scholarship. According to Downes (1998), some individuals observe stylistics as a type of linguistics that leads with the study of language varieties, principals behind choice, accent, length, register, dialogue, and its properties. The specific choices are explained from the attempts that as certain principles established by people and social groups to use language (Birch, 1995). These summate arguments demonstrate that style is central to the study of stylistics.

A writer's style is an echo of the author's personality, idiosyncratic features and unique voice. According to Leech (1969):

"Style is a selection of linguistic; a sort medium of revolt against the norm; a repetition of linguistic forms. Style also defines the personality of person. Style shows the thoughts and ideas of a person. Leech views that the structure of words should be changed in order to get clarity in diction."

There are four types of style. These are: expository or argumentative style, descriptive style, persuasive style and narrative style. Expository style explains and communicates an issue to the addressee and concludes an individual's own perspective about that issue. In descriptive style, a writer focuses on greatly describing an event or situation in great detail and is used in poetry or journal writing. In the persuasive style, the writer persuades the reader towards adopting his perspective on specific subjects. Whereas, narrative style narrates any type of story or incident in literary or non-literary genres.

\subsection{The Domain of Style}

The characteristic style of a work or a writer may be analyzed in terms of diction, or characteristic choice of words, sentence structure and syntax, the density and types of its figurative language, patterns of its rhythm, sound components, and its rhetorical aims and devices. Styles are comprised of three major levels in traditional rhetoric theories, which include the base or plain, the mean, and the grand style. The levels of style in a work are required in the doctrine of decorum in an adequate work to the occasion, the dignity of its literary genre, and to the speaker. Recently Northrop Frye introduced a variant of this ancient and long-persisting theory of stylistic levels in literature. A basic differentiation between the demotic style (which is modeled on the language, rhythms and association of ordinary speech) and the hierarchic style (which employs a variety of formal elaborations that separates literary language from ordinary speech) was made. Frye proceeded to differentiate high, middle and 
low level in each of these classes. In analyzing style, two different types of sentence structure were conventionally differentiated, namely the periodic sentence and non-periodic sentence. In periodic sentences, the components are closely interwoven to the degree that the meaning remains suspended until the end of the sentence. This is a fabricated example:

"In a highly attended new American civilian court, the size of the vast building of the faculty of Arts and Science in Delhi University, where he used to be present every three weeks with his father, the strong young Indian man who was holding a long legal petition in his right hand had displayed an outrageous red cheek towards the jury who sentenced him three months imprisonment for his rude behavior with the judge during the trail of his elderly brother."

Another example is presented from the opening sentence of Boswell's life of Samuel Johnson:

"To write the life of him who excelled all mankind in writing the lives of others, and who, whether we consider his extraordinary endowments, or his various work, has been equaled by few in any age, is an arduous and may be reckoned in me a presumptuous task."

Non-periodic or loose sentences are more relaxed in effect and have contiguous components, as highlighted:

"He will tell you the names of the principle favorites, repeat the shrewd saying of a man of quality whispered an intrigue that is not yet blown upon by common fame; or, if the sphere of his observations all incidents, turns, and revolutionist a game of ombre, when he has gone thus far he has shown you the whole circle of his accomplishments, his parts are drained, and he is disabled from any further conversation."

A distinction is also drawn between parataxis and hypotaxis style. A parataxis style is when the writer put the elements in a sentence or a sequence of complete sentence one after the other without cohesive ties. Hemingway's writing style is an example of paratactic style:

"It was dim and dark and the pillars went high up, and there were people praying, and it smelt of incense, and there were some wonderful big buildings."

The curt sentences in 'Indian Camp' omit all connectives:

"The sun was coming over the hills. A bass jumped making a circle in the water. Nick trailed his hand in the water. It felt warm in the sharp chill of the morning."

In a hypotactic style, the temporal, logical, and syntactic relations between members and sentences are expressed by cohesive ties such as 'however', 'hence', 'again' and so on. The types of style are categorized as 'pure', 'ornate', 'florid' and so on. Styles are also classified according to literary period or tradition (such as metaphysical or Restoration prose styles); according to an influential work (such as biblical styles or euphemism); according to type of use (such as scientific styles or 'journalese'), or; according to distinctive author practices (such as 'Shakespearian' or 'Miltonic' styles).

\subsection{Stylistics and Style}

Foregrounding is a kind of textual patterning with respect to literary aesthetic aims (Krishnamurthy, 2010). It can occur on all textual levels, such as phonology, syntax, and semantics. It is generally used for highlighting important text portions to aid memorability and/or to invite interpretation. Foregrounding is accomplished either by deviating from the linguistic norms (style as deviation) or parallelism. In parallelism, foregrounding is prompted by a complete and accurate adherence to the linguistic rules, rather than stepping outside the rules as is the case with prominence through style deviation. Parallelism can be accomplished by many ways, one of which is the repetition of lexical items or the grouping of words from the same area of association in a text. Another general possibility is varying linguistic features while holding others constant. Here, one of the most famous examples is from Othello:

\section{"I kissed thee ere I killed thee."}

This sentence consists of two matrix clauses coordinated by the conjunction 'ere'. A stylistic analysis of this sentence at different linguistic levels has been presented. Firstly, complete parallelism is observed at the level of phenetics. Both the subject of the two clauses are 'I', the object of the two clauses are 'thee' and although the verbs of the two clauses "kissed" and "killed are different, they are still parallel to each other in a few ways. For instance, phonetic $/ \mathrm{kist} /$ and $/ \mathrm{kild} /$ have phonetic parallelism through the alliteration of the repeated word-initial $/ \mathrm{k} /$ and the similarity of the word-final /d/ and / $\mathrm{t} /$, which share two out of three distinctive phonemic features. They are both alveolar stops. They are different only by virtue of the fact that $/ \mathrm{d} /$ is voiced, whereas $/ \mathrm{t} /$ is voiceless. They are also different by the consonance $/ \mathrm{s} /$ and $/ 1 /$, which are voiced and voiceless respectively. The two words also consists of one syllable, each with the same structure cvcc. 
Secondly, at the level of spelling, there is only one difference between the spellings of the two words. This is in the form of the double /s/ and double /1/. Even here, there is parallelism due to the doubling. Thirdly, at the morphological level, both words consist of two morphemes, the second of which is a past tense marker. Fourthly, at the syntactic level, both the matrix clauses are parallel. The subjects in both the clauses are the first person singular 'I'. Similarly, the objects in both the clauses are the second person singular (thee). The two verbs 'kissed' and 'killed' within the two parallel matrix clauses are parallel because both of them are mono-transitive verbs. The parallelism of the two matrix/super-ordinate clauses makes the line foregrounded, thereby lending them an interpretative significance. The parallelism illuminates the meaning of the line said by Othello immediately after killing Desdemona. The two independent/matrix clauses are therefore opposing each other.

'Kiss' is related to the theme of love or life or sanity in Othello and 'killed' is related to the theme of hatred, jealousy, or madness. However, 'kissed' and 'killed' are not antonyms of each other if they are looked at outside the context like 'love' and 'hate'. The former is a source of love, happiness, fertility, creation, and jubilation; whereas, the latter is a source of annihilation, death, destruction, sadness, or mourning. The context compels one to look at the two opposing words since normally, they would not be looked at in this way. The readers attempt to interpret these items as being parallel in meaning, due to the parallelism effect. This particular relation is exhibited by a processing tendency. The readers attempt to interrupt relationship in this manner, when readers encounter such parallel structures. Therefore, the line may be interpreted as per stylistic analysis as follows. It could be that Othello lost his mind and was rendered insane, thereby being unable to differentiate between kissing, which is a source of life, and killing, which is a source of death. This interpretation is indicated by the formal stylistic analysis of the line. The line is divided into two main clauses connected by the conjunction 'ere' suggesting that the matrix clause before 'ere' is equal to the matrix clause after 'ere' both formally and semantically. The conjunction 'ere' itself indicates the parallelism and equality. ' $E$ ' before ' $r$ ' is equal to ' $E$ ' after ' $r$ '. It is seen that 'ere' represents the scale of weight or the symbol of justice on the court of justice; whereas, deviation can be seen as unexpected irregularity such as 'a grief ago'. There is syntactic deviation of the phrase 'a grief ago'. The determiner 'a' (the meaning of which is 'one'), the definite article, indicates that the head of the noun phrase is a countable noun, meaning that it can be pluralized (for example, a cat, cats; a box, boxes; a building, buildings and so on). However, unlike this, sadness and happiness cannot be pluralized. Therefore, the determiner 'a' pre-modified an abstract noun 'grief'. Similarly, the post-modifier adverb of time has to post-modify a noun a countable time related to time. On the contrary, grief is a word that is related to emotions.

It is observed that a noun paradigm which can fit to the frame ' $a+$ countable noun of time+ago' is violated from the above analysis and juxtaposed normal and deviated paradigms.

Table 1. Comparison of normal and abnormal paradigms

\begin{tabular}{ll}
\hline Normal Paradigm & Abnormal Paradigm \\
\hline A minute ago & a pain ago \\
An hour ago & a severing ago \\
A day ago & a sadness ago \\
A week ago & an enjoyment ago \\
A year ago & a sickness ago \\
\hline
\end{tabular}

It is very obvious that 'a grief ago' is highly noticeable. The fact that it is linguistically deviant has an emotional impact on the reader. The phrase is unusual and stands out for the reader, since the reader is not familiar with such collocation in the linguistic structure. There is a change in the way the phrase is interpreted, due to this foregrounding. The reader will be forced to consider the foregrounded textual portions and compare this with normal paradigms, due to which the meaning will be eliminated from the comparison. In the normal paradigm, time is considered in minutes, hours and the like; however, the abnormal paradigm describes time in terms of sadness or suffering. The reader arrives at this interpretation by comparing the semantic characteristic of what actually occurs with what must occur. This method is useful for metaphorical expressions. Stylistics search for noticeable regularity, harmony, consistency in linguistic patterns and structures of a text in context. This appears in the form of stylistic devices such as graphological details (commas, full stops, apostrophe), phonological details (alliteration, assonance, consonance, rhyme scheme), monosyllabic words, disyllabic words, personification, imagery, similes, diction, rhetorical question, personifications, tone and mood and parallelism in the structure or the meaning as in the example above.

There is parallelism observed in the following line of poetry from Alexander Pope's 'The Rape of the Lock': 
"Puffs, powders, patches, bibles, billets-doux."

The poet juxtaposed these nouns that are not congruous in respect of meaning but grammatically all plural nouns make the reader believe that they are similar. Similarly, these words are initially alliterated at the level of phonetics. The writer makes the reader think elements that are similar in form, are also similar in meaning for Lady Belinda. Since the Bible, which is a holy book, is placed beside items of make-up, it is clear that Lady Belinda holds the Bible at the same level of respect as puffs, powders, patches and billets-doux. Therefore, stylisticians do not analyze the language for its own sake, but to justify their interpretation. They use the form as a means of proving their interpretation. That is, they use the forms to display their functional significance for the interpretation of a text. Therefore, the goals of stylistics are to demonstrate the oddity, anomaly, abnormality of a text. It stimulates our enjoyment of text by drawing our attention to different text manipulations. The association of interpretation of a text to its linguistic forms is an advanced stage of systematizing the interpretation as observed above in the connection of the interpretation of the form to the meaning in the verse. "I kissed thee ere I killed thee" and "Puffs, powders, patches, bibles, billets-doux".

A stylistician applies stylistics on a text for the purpose of evaluating a text like a critic; however, the difference between the stylistician and the critic is that the former embarks on the linguistic analysis arrive at the evaluative judgments and the later immediately jumps to give value judgments impressionistically and subjectively. A stylistician gives description of the physical appearance of a literary text, through the graphological, syntactic features and lexicon-semantic features. The effects are created by the various sentence types in a text. The aspects such as ellipses, parataxis, hypotaxis, and right and left-branching sentences are considered significant and stylistic use of words here may produce denotative, connotative, collocative, affective, thematic, or stylistic meanings based on the speaker's or writer's intention. Certain characteristic use of words may help us to identify the context of a text, its genre, its communicative purposes, its author, and so on. Stylistics is a bridge between linguistics and literature. It is the linguistic study of style applying techniques and concepts of modern linguistics to the study of literature. It is concerned with the available choices and the explanation of the reason for particular choices.

According to Birch (1989), "language and style are allowed to move in a fix boundary on the greatness of words." He additionally says that, "words have special meanings which create distinctions between them."

Whereas, Short (1996) expresses that it is not merely the linguistic forms of texts that are important but also the meaning of the text in the sense of the plot and overall message of a piece of work. To him, "Stylistics can sometime look like either linguistics or literary criticism, depending upon where you are standing and where looking at."

Thus, the nature of stylistics is the linguistic analysis of a text to accomplish its aesthetic evaluative objective in various contexts, specify its purpose and style, and arrive at the meaning of the literary or nonliterary work of art through the techniques of stylistic analysis of language form and content.

\section{Literary Criticism}

The only difference between stylistic analysis and literary criticism, is that literary criticism goes directly to its text evaluation subjectively and is impressionistically independent from the linguistic form of the test. The presence of literary criticism has been studied extensively in the literature. Aristotle wrote the poetics, description of literary forms, and a typology with number of particular criticisms of contemporary art works. Moreover, the critics of Plato was more argued in terms of false, imitative, and secondary formative. Later, classical and medieval criticism often focused on religious texts, and the several long religious traditions of hermeneutics and textual exegesis have had a profound influence on the study of secular texts. In the 9th century, literary criticism was further deployed in the form of Arabic poetry and medieval Arabic literature usually by Abudllah ibn al-Mu'tazz in his Kitab al-Badi and Al-Jahiz in his al-Bayan wa-'l-tabyin and al-Hayawan. Literary criticism passes though different development periods, such as classical and medieval criticism, Renaissance criticism, Enlightenment criticism, 19th-century Romantic criticism, and New Criticism.

Literary criticism is the practical application of literary theory. It tries to clarify the importance of a text by explaining the text independent from the form of the text of the linguistic aspects of a text. A critic may seek the help of extra textual factors such as the milieu, socio-politics and geography, but leaves out the linguistic aspects of the text. Both the stylistician and literary critic opt for decoding a literary or nonliterary unfamiliar text to the public and recoding it in a familiar communal form so that it can be understood and relevant to unspecialized man with different approaches. For example, a critic would say that Othello lost his mind and became a mad man for considering the source 'life' and 'kissed', to be parallel to the source 'death' and 'killed'. However, the stylistician would start by analyzing the text linguistically, as in the example "I kissed thee ere I killed thee" 
previously analyzed and linguistically explained. In other words, a critic is sensitive to language but his concern is the underlying massage and not the way the signals are combined. The literary stylistician is interested in the aesthetic experience, the perception of reality in a text according to the intuition of the author, and the evocative and figurative language that invokes strong images, memories, or feelings to mind. However, the stylistician is not concerned with the formal analysis of language. When a critic analyzes a literary work, he will focus on presenting the themes; he will not talk about issues such as tone and mood, graphological details, phonological details, alliteration, assonance, consonance, monosyllabic words, disyllabic words, personification, imagery, similes, diction, and rhetorical questions. Literary criticism undertakes the interpretation of a text as the ultimate objective of analysis. The magnificence, elevated glamorous linguistic style has supreme importance for literary criticism; however, language system is not important in itself. It is interested in the overall kaleidoscopic panoramatic view depicted by verbs, nouns, adjectives, adverbs, prepositions and conjunctions, phrases paradigms, clauses, without naming these elements of grammatical devices. The interpretation of a text is based on sentence elements with detachment from them as they form components. Their functions, semantic significance and effect are given the upper hand in the critical process of literary or nonliterary work; whereas, stylistics studies the linguistic features of a text. It specifies various linguistic choices made by the author as well as the effects of the choices. The use of language and its effects in a text is an initial stage for explaining the meaning of a text.

The difference between stylistics and literary criticism was explained by Ayeomoni (2003), where it was discussed that literary criticism focuses on subjective interpretation of texts, whereas stylistics focuses on the 'linguistic frameworks operative in the text'.

Linguistic analysis of text is verifiable by the parameters of linguistic usage. Contrarily, literary criticisms will response to the text emotionally. Since there are two elements to literature, the artistic and the verbal, Hassan (1985) and Ayemoni (2003) have notified that linguistic stylistics accepts the assumption that it is not sufficient to explore the literary texts language. The core rationale of linguistic stylistics is to associate language use in literary texts to its artistic function in view of this factor. Therefore, language is not studied in isolation of the artistic function when it is used in the text. On the other hand, it is investigated for establishing the use of language expressed by the writer to express his message.

\subsection{Deconstructing Stylistics and Literary Criticism}

A literary or non-literary text, whether oral or written, is produced through the continuous process of continuously choosing preferable linguistic structures and words and rejecting others; that is, the writer or the speaker selects a specific word from a language to construct a phrase, a clause, and sentences and consequently, a whole discourse according to the context, the social status of the addressor and the addressee, the intention of the sender and the pragmatic state of the receiver. Moreover, as a language user one can give evaluative judgments about the linguistic structure, meaning, the choice of lexes and colocation of words. This evaluative judgment always varies from being highly subjective, intuitive, and impressionistic to highly objective, impartial and rational and a scientific statement based on facts and rules of grammar.

For example, statements such as 'She is very good' or 'Ahmed's language sounds flowery and fancy' are subjective, intuitive, and impressionistic. However, one can be very straightforward and technical, such as by saying 'She is 160 centimeters tall'. The use of flowery and overly-poetic adjectives (subjective, intuitive and impressionistic) and highly objective, rational, impartial and truthful words, phrases and statements is an example of analytically sensitive language-awareness, or close-reading. If the person making the comments possesses a little technical knowledge of how language really works, he or she would end up with literary criticism; contrarily, the one who knows the linguistic science will end up with stylistic analysis.

These impressions can begin to be considered as being analytical, though one might say they are examples of sensitive language-awareness, or close-reading. If the person making the comments also possesses a little technical knowledge of how language really works, then their observations are likely to be less impressionistic. The frequent pre-modification with archaic lexis creates a self-consciously poetic effect. However, if the writer or the speaker is very cognizant of the linguistic principles and rules of grammar in their analytical commentary on a text, then they will be more objective, rational and impartial. For example, using "She left a grief ago", the commentator could say that the speaker of this phrase goes under suffering and pain because he counts his life in terms of grief and pain. Contrastively, a stylistician or commentator could begin by systematically analyzing the linguistic structures to find a linguistic justification for his judgment. For instance, the head of the noun phrase paradigm 'a grief ago' is 'ago', which is usually pre-modified by a countable noun of time, such as a minute, an hour, a week a month, a year, a decade, a century, and millennium. Therefore, the commentator can assert on the 
basis of the modified and the pre-modifier, that the speaker goes under suffering and pain because he counts his days in terms of grief. The stylistics can be seen as a logical extension of moves within literary criticism early in the twentieth century to concentrate on studying texts rather than authors. Thus, stylisticians have moved away from the study of style and towards the study of how meanings and effects are produced by literary texts. For example, a stylistician will go through the following stages in order to give an evaluative judgment on the line "I kissed thee ere I killed thee". This line from Shakespeare is highly foregrounding because of the complete parallelism at the morphological level. The first part of the sentence is morphologically parallel with the second; that is, 'I' is a word consisting of one morpheme, which is the subject of the verb 'kissed', and the same yard stick can be applied to the subject of the verb 'killed'. The verbs themselves in the two parts of the sentence consist of two morphemes, where one is bound and the other is free in both the verbs; both of these objects are also one morpheme word. Therefore, there is a complete parallelism at the morphological level.

At the grammatical and syntactic level, a complete parallelism is also seen; that is, both parts of the sentence are independent clauses having subject plus mono-transitive verb and object. At the level of the phonological analysis, there is a complete parallelism; that is, the subjects in both the clauses are the same 'I', the verbs of the two clauses begin with voiceless $/ \mathrm{k} /$ and the vowel $/ \mathrm{i} /$, end with consonants almost produced from the same place of articulation and have the same past tense morphemes /ed/. Similarly, the object is the same in the two independent clauses. Even the conjunct is parallel, as seen by the $/ \mathrm{r} /$ being preceded by /e/ and proceeded by the same. Therefore, there is a complete parallelism at the level of syntax.

At the level of the analysis of semantics, the writer draws a parallelism between the two clauses; since the two clauses are parallel at the phonological, morphological and syntactic levels, it must mean that they are also parallel at the semantic level. For instance, Othello had become a madman because he had equated two contrary things such as 'kiss' and 'kill. The intended meaning in the source language is that Othello was a madman who could not differentiate between contrary things. Therefore, it is clear that stylistics covers all the psychological aspects, as exemplified by Othello, who committed a heinous and barbaric crime under psychological trauma. These sorts of analytical comments are more precise; they draw on a systematic description of language from the discipline of linguistics and account for an initial intuitive response: they are examples of stylistics.

This critical simple analysis or even simply discourse text analysis, with stylistics now largely being reserved is also sometimes called literary linguistics. Stylistics combine the use of linguistic analysis with the psychological processes involved in reading, depending on the study of linguistics and psychology. The term 'stylistics' became associated with detailed linguistic criticism because stylistics explore how readers interact with the language of mainly literary texts, to explain how we understand and are affected by texts when we read them.

The techniques of deviation from and parallelism with the norms are the two principle techniques, in which structures are patterned in some way making them psychologically salient or 'foregrounded' for readers. The language of the texts is not analyzed very much by critics, except for when they read and pay very close attention to the text and then describe how they understand them and are affected by them. For example, in the above stated example, the readers unconsciously are convinced that Othello has become a mad person through the tactful parallelism of the structures and linguistic patterns to insinuate that there is a parallelism between death and life. These two contrary things became the same for the psychological disturbed person. He degraded from a highly attractive and commanding personality to a mere brutish being.

Stylistics might make efforts to ascertain principles enabling to explain specific assertions made by people and social groups as a conceptual discipline in their language use. For instance, the reception of genre, the study of spoken dialects and register, the literary production, and study of folk art, and areas, which include literary criticism and discourse analysis are included in a conceptual discipline. Stylistics created some high parameters of judgment, which to some extent are scientific conclusions instead of unsubstantiated impressionistic judgments. There is a great shift from overall subjective and impressionistic criticism to criticism which is distinctly formalist in character. It stresses close attention to the internal characteristics of the text itself and discourages the use of external evidence to explain the work. The method of stylistic criticism is foremost a close reading that concentrates on formal aspects such as rhythm, meter, theme, imagery, metaphor and so on. The interpretation of a text shows that these aspects serve to support the structure of meaning within the text as previously evidenced.

Both literary criticism and stylistics attempt to commend and expose a work of arts. The only difference between the two approaches is that in the former, a critic expresses his own opinion of what the text means, whereas, a stylistician offers structural evidence to support his interpretation of the meaning. Eliot's views on criticism may also be considered to suggest further the claims of literary criticism and the concerns of stylistics. His views are 
derived from his perspective on art and tradition. He defines criticism as, "the commendation and exposition of works of art by means of written words". Criticism can never be an autotelic activity, since it is always about something. Art, as critics like Matthew Arnold point out, may have other moral, religious, cultural ends, but art performs its function better by being indifferent to such ends. However, criticism always has only one definite end, which is, 'elucidation of works of art and the correction of taste'. Nevertheless, illustration of work arts shifted the focus from extrinsic factors to intrinsic factors. In his essay 'The Frontiers of Criticism', he further explains the aim of criticism as, "the promotion of understanding and enjoyment of literature". This should be the aim of both stylisticians and literary critics.

\subsection{The Need for Co-Operation and Conformity}

It might become simple to identify whether a critic has executed his function adequately or not since the end of criticism is apparent and clearly defined. On the other hand, this aspect is not easily defined and justified. The difficulty emerges from the fact that critics demonstrate extreme observations and passionately imply their individuality, rather than attempting to discipline their individual prejudices and impulses and implementing their differences with several critics as plausible and cooperating in the common interest of actual judgment. This is so because they owe their livelihood to such differences. Such critics are worthless since they mainly compete with each other to attract as large an audience as possible. On the other hand, there are specific other critics who are beneficial and it is referred based on their works that are ascertained based on the objectives and approaches of criticism, which must be implemented comprehensively.

The stylistics narrow the gap of differences between different opinions since the evaluation of a literary text is based on the structural evidences to avoid the dilemma of differences in the opinions and judgments of literary evaluators and commentators. In other words, the inner voice in literature is no more the only dominating factor in literary criticism and has been rejected far before the emergence of the stylistic approach to literary criticism.

The views of Middleton Murry are dismissed by the summary of Eliot with an emphasis of light ridicule in the third part of the essay. Murry disrespectfully argues the inner voice wiggery for individuals who assumed the inner voice as the criticism function for discovering few common principles in order to achieve artistic perfection. There are no desires of any principles for those who believe in the inner voice. In other words, the accumulated wisdom and experience of ages are resultant from the obedience to the laws of art and to tradition, which needs care for perfection in art. Therefore, it is obvious that stylistics is a rebellion against the traditional approach to literary criticism. Stylistics is different from the theory of reader response, where the reader is given the full authority to interpret literary work according to his psychological state.

\subsection{Reader-Response Theory}

The reader-response criticism is a school of literary theory that focuses on the reader or 'audience' and his or her experience of a literary work, in contrast to other schools and theories that focus attention primarily on the author or the content and form of the work. Let us consider what Ronald Barthes has to say about the movement between the text to context. The text is multi-dimensional space where a variety of texts, none of which are original, bend and clash. The text is a tissue of quotation. The statement focuses on the movement from the text to the context and so does stylistics as it deconstructs the structure and the contents to be read separately. Style is basically individualistic; it entails a variety of influences which might be a confluence of references from global scholarship. For example, the easy evolution of styles from the early to the mature period as a writer while being exposed to a wide array of dialects allows his style to be influenced by them to the extent that there will be an apparent difference between the many stages of his writings. Polyglots have a tendency to change their styles.

Modern reader-response criticism has been commenced in the 1960s and 70s even though theory has long given some attention to the role of reader to create the emphasis and experience of a literary work. For instance, Hans-Robert Jaus and Roland Barthes, Normal Holland, Stanley Fish, and Wolfgang Iser are amongst the writers in this specific era. A group of Cambridge undergraduates mis-readings is investigated from the significant predecessors of IA Richards (1929) who criticized that it is essential for the teacher to ignore implementing any preestablished ideas regarding the appropriate approach to response to any work (Rosenblatt, 1938). The reader as an active agent is recognized by the reader-response theory who implements actual existence to the work and concludes its essence using interpretation. It has been argued that literature must be observed as a performing art in which unique and text-related performance is created by the reader based on his or her own. On the other hand, the theories of New Criticism and formalism are totally opposite to the reader-response theory. The meaning of a text is emphasized from the new criticism, where no response to the intention or authority nor the psychology of the reader was allowed in the orthodox New Critics discussions. 


\subsection{Tenets of Classical Criticism}

The history of literary texts traditionally has recognized the importance of creation as inspiration to reach a high degree of exaltation. The classical criticisms from Horace, Longinus to Aristotle and Plato have reaffirmed the literary value of the text in terms of its accessibility to the realms of idealism with an eye on reaching the sublime state. The art has to be sublime to be different from the ordinary, as evidenced by the works of Shakespeare and Milton.

\subsection{Renaissance Criticism}

The literary criticism of the Renaissance developed classical ideas of unity of form and content into literary neoclassicism, proclaiming literature as central to culture and entrusting the poet and the author with the preservation of a long literary tradition. The birth of Renaissance criticism was in 1498, with the recovery of classic texts, most notably, Giorgio Valla's Latin translation of Aristotle's Poetics. The work of Aristotle, especially 'Poetics', was the most important influence upon literary criticism until the late eighteenth century. Lodovico Castelvetro was one of the most influential Renaissance critics who wrote commentaries on Aristotle's 'Poetics' in 1570.

\subsection{Enlightenment Criticism}

The Enlightenment began about three centuries ago. It was an intellectual movement centered upon the realization that the world is not impossibly mysterious but makes sense; that science and rationalism can give us authentic truth, and thus the means for better lives. This is the essence of the modern mindset. Yet it has its detractors, who mainly paint it as mere Western ethnocentrism. The Enlightenment did arise in the West. However, its appeal was not in its 'Western-ness' but, rather, its human universality. Multiculturalists who say that rationalism is something peculiarly Western are actually insulting non-Western cultures.

The Counter-Enlightenment was a movement that arose in the late-18th and early-19th centuries in opposition to the 18th century Enlightenment. The term is usually associated with Isaiah Berlin, who is often credited with coining it, perhaps taking up a passing remark of the German Philosopher Friedrich Nietzsche, who used the term 'Gegen aufklärung' at the end of the 19th century. It has not been widely used since. The first known use of the term 'counter-enlightenment' in English was in 1949. Berlin published widely about the Enlightenment and its enemies and did much to popularize the concept of a Counter-Enlightenment movement that he characterized as relativist, anti-rationalist, vitalist and organic, and which he associated most closely with German Romanticism. Some recent scholarship has challenged this view for focusing too narrowly on Germany and stopping abruptly in the early 19th century, thereby ignoring the Enlightenment's many subsequent critics, particularly in the 20th century. Some scholars reject the use of the term 'the Counter-Enlightenment' on the grounds that there was no single Enlightenment for its alleged enemies to oppose.

\subsection{The Biographical Literary Criticism}

The life of the person is investigated from the biographical literary critics who believed that a work can be explained based on the writer's writeup. On the other hand, there is a major difference between the biographical criticism and the biography of a person. The biographical criticism is concerned with the historical events of a person as compared to add emphasis into the work that the individual developed. In addition, the person's biography is the historical information of a person that implies on its own merit. There are several issues with a biographical criticism that must be accounted by the biographical critics. The biggest issue is that writers are more included to exaggerate on the facts of individuals lives as they are all writers. Occasionally, specific undesirable facts of his or her history or make up things are concealed by a successful author that never occurred in real life or leave out significant life events that did not occur. Another risk is the potential for the biography of the writer to overwhelm his or her work for the biographical literary critic.

\subsection{9th Century Criticism}

The British Romantic movement of the early nineteenth century introduced new aesthetic ideas to literary study, which included the idea that the object of literature need not always be beautiful, noble or perfect, but that literature itself could elevate a common subject to the level of the sublime. German Romanticism, which followed closely after the late development of German Classism, emphasized an aesthetic of fragmentation that can appear startlingly modern to the reader of English literature and valued Witz - that is, 'wit' or 'humor' of a certain sort-more highly than the serious Anglophone Romanticism. The late nineteenth century brought renown to authors known more for critical writing than for their own literary work, such as Matthew Arnold. 


\subsection{Practical Criticism}

The USA New Criticism shared two important features with studies of authors in the 19th and 20th centuries. Primarily, an emphasis was laid on the language of the text rather than its author. Additionally, very close attention was paid to the language of texts when reading them, by describing how readers understood them. This approach is often called Practical Criticism. It is matched by a similar critical movement in the USA which is associated with Cleanth Brooks, René Wellek, Austin Warren and others, called New Criticism. New Criticism was a movement in literary theory that dominated American literary criticism in the middle decades of the 20th century. It emphasized close reading, particularly of poetry, to discover how a work of literature functioned as a self-contained, self-referential aesthetic object. New Criticism developed in the 1920s-30s and peaked in the 1940s-50s. The movement is named after John Crowe Ransom's book The New Criticism which was published in 1941, as cited in Cain (2018, p. 11). New Critics often performed a 'close reading' of the text and believed the structure and meaning of the text were intimately connected and should not be analyzed separately. Before the New Criticism became dominant, English professors in America focused their writings and teaching on historical and/or linguistic scholarship surrounding literature, rather than analyzing the literary text itself. New Criticism was never a formal collective, but it initially developed from the teaching methods advocated by John Crowe Ransom who taught at Vanderbilt. Some of his students such as Allen Tate, Cleanth Brooks, and Robert Penn Warren would go on to develop the aesthetics that came to be known as the New Criticism. In 1946, William K. Wimsatt and Monroe Beardsley published a classic and controversial New Critical essay entitled 'The Intentional Fallacy', in which they argued strongly against the relevance of an author's intention, or 'intended meaning' in the analysis of a literary work (Wimsatt \& Beardsley, 2014).

New Criticism is distinctly formalist in character. It stresses close attention to the internal characteristics of the text itself and discourages the use of external evidence to explain the work. The method of New Criticism is foremost a close reading, concentrating on such formal aspects as rhythm, meter, theme, imagery and metaphor. The interpretation of a text shows that these aspects serve to support the structure of meaning within the text. In the Verbal Icon published in 1954, William Wimsatt and Monroe Beardsley describe two other fallacies which are encountered in the study of literature (Ferguson \& Mackay, 2018, pp. 425-431). The 'Intentional Fallacy' is the mistake of attempting to understand the author's intentions when interpreting a literary work. Such an approach is fallacious because the meaning of a work should be contained solely within the work itself and attempting to understand the author's intention violates the autonomy of the work. The 'Affective Fallacy' is the mistake of equating a work with its emotional effect upon an audience. The new critics believed that a text should not have to be understood relative to the responses of its readers; its merit and meaning must be inherent. In 'The Function of Criticism', TS Eliot defines criticism as understanding and enjoying literature which he however modifies in frontiers of criticism as a means of getting essence in literary text.

\subsection{New Criticism}

The current ideas about literary criticism are derived almost entirely from the new direction taken in the early twentieth century; although, the aesthetic movements were important as antecedents. Early in the century, a school of criticism known as Russian Formalism, and slightly later the New Criticism in Britain and in the United States, came to dominate the study and discussion of literature in the Anglo speaking world. Both schools emphasized the close reading of texts, elevating it far above generalizing discussion and speculation about either authorial intention (to say nothing of the author's psychology or biography, which became almost taboo subjects) or reader response. This emphasis on form and precise attention to 'the words themselves' has persisted, even after the decline of these critical doctrines themselves.

Where New Criticism was based almost exclusively on the description of literary works as independent aesthetic objects, Practical Criticism tended to pay closer attention to the psychological aspects involved in a reader's interaction with a work. Stylisticians hold the opinion that text should be analyzed in detail rather than simply relying on intuition. Stylistics is derived from earlier critical approaches associated with Practical Criticism and New Criticism. It can be used equally effectively on literary as well as non-literary texts. However, stylisticians prefer to deal with literary texts because of the glaring foregrounding, back-grounding and parallelism found on a wide skill in literary texts. The genesis of deconstruction lies in the emergence of new criticism as the pioneers of new criticism advocated a more sustained focus on the text itself rather than stressing the background of a writer's life. Deconstruction can be construed in terms of an extension of New Criticism, given the fact that it recognizes the importance of a close reading of a text while declaring it unstable

\section{Deconstruction}

Deconstruction is the key to the movement from the text to context. A close reading of texts is involved in the 
deconstruction to demonstrate that any provided text has irreconcilably opposing meanings as compared to a logical or unified deconstruction. It is not a disassembling of the text structure, but an identification that it has already disassembled itself. It is clearly solid ground with not rock as compared to air.

The French philosopher Jacques Derrida has created the meaning of deconstruction and argued that individuals must explore and express their perceptions with respect to the binary oppositions in Western culture. Deconstruction emerged as a reaction to formalism and structuralism even though its ultimate objective might be to argue western logic. All elements of human culture such as literature might be revealed as components of a signs of system as suggested by structuralists. Derrida did not believe that Structuralists could explain the laws governing human signification and thus provide the key to understanding the form and meaning of everything from an African village to a Greek myth to a literary text. He also rejected the structuralist belief that texts have identifiable 'centers' of meaning - a belief Structuralists shared with Formalists.

Formalist critics, such as the New Critics, assume that a work of literature is a free standing, self-contained object whose meaning can be found in the complex network of relations between its parts. Deconstructors, by contrast, see works in terms of their undecidability. They reject the Formalist view that a work of literary art is demonstrably unified from beginning to end, in one certain way, or that it is organized around a single center that ultimately can be identified. As a result, Deconstructors see texts as more radically heterogeneous than do formalists. Formalists ultimately make sense of the ambiguities they find in a given text, arguing that every ambiguity serves a definite, meaningful, and demonstrable literary function. Undecidability, by contrast, is never reduced, let alone mastered. Though a deconstructive reading can reveal the incompatible possibilities generated by the text, it is impossible for the reader to decide among them.

Modern literary criticism is often informed by literary theory, which is a philosophical discussion of its methods and goals. Though the two activities are closely related, literary critics are not always, and have not always been, theorists. Whether or not literary criticism should be considered a separate field of inquiry from Literary theory, or conversely from book reviewing, is a matter of some controversy. For example, the 'Johns Hopkins Guide to Literary Theory and Criticism' draws no distinction between literary theory and literary criticism and almost always uses the terms interchangeably to describe the same concept. Some critics consider literary criticism to be a practical application of literary theory, because criticism always deals directly with particular literary works, while theory may be more general or abstract.

\subsection{Some Sign Posts for Stylisticians}

It is important to specify the features that a stylistician looks at in a text analysis. These features would be serve as a guideline for the stylistician. The first is repetition of lexis. Here, the same word might be repeated, or synonymy or near synonymy may be used.

For instance, in West Land, Eliot said:

"Water, water everywhere and no drop to drink."

Here, Eliot repeated the word 'water' to emphasize the vast availability of religious guidance, a source that no one availed even though it was so prevalent. Another feature of importance in stylistic text analysis is to analyze at the lexico-semantic level. This is a subfield of linguistic semantics and is also known as lexicosemantic. The units of analysis in lexical semantics are lexical units which include not only words, but also sub-words or sub-units such as affixes and even compound words and phrases. The study of lexical semantics looks at: the classification and decomposition of lexical items, the differences and similarities in lexical semantic structure cross-linguistically, and the relationship of lexical meaning to sentence meaning and syntax (for instance, hyponymy, hypernymy, synonymy and antonym).

\subsection{Three Basic Principles Behind the Practice of Stylistics}

According to Simpson (2004), stylistics should conform to the three basic principles, which are cast mnemonically as the three 'Rs'. The three Rs stipulate that stylistics should be rigorous, retrievable, and replicable. According to Simpson, 'rigorous' means that it should be based on an explicit framework of analysis. Stylistic analysis is not the end-product of a disorganized sequence of ad hoc and impressionistic comments but is instead underpinned by structured models of language and discourse that explain how various patterns in language are processed and understood.

The analysis is structured using explicit terms and criteria to critic that the stylistic approach is retrievable and the essence of which are approved upon by other stylistics students. There is an emphasis of agreement regarding the stylistics terms even though appropriate definitions have approved difficulty for some elements. Other stylistics re allowed by the consensus in order to approach the stream implemented in an investigation for testing 
the analysis and to retrieve the stylistic method.

\subsubsection{Syntactic Level}

Syntactic level deals with the set of rules, principles, and processes that govern the structure of sentences in a given language. Syntax studies the construction of words into phrases, phrases into clauses and clauses into sentences. For example, the phrase 'a minute ago' is the normal paradigm for the previously stated and analyzed abnormal paradigm phrase 'a grief ago'. The previously stated and stylistically analyzed compound sentence, "I kissed thee ere I killed thee", has the construction SVO+ conjunction 'ere' SVO, that is, two independent clauses each of which consist of subject, transitive verb and direct object joined by the conjunction 'ere'. The study of these elements is related to the syntactic level. On the basis of syntactic studies, a stylistician would be able to judge whether a syntactic pattern is foregrounding on the bases of parallelism or deviation. Therefore, it is necessary for a stylistician to be knowledgeable of the analysis of linguistic levels. However, a critic does not need to be able to linguistically analyze the levels of language. This is a significant difference between a stylistician and a literary critic who builds his judgement and evaluative approach to a work of art using an emotional and subjective approach.

\subsubsection{Misconception About the Scope and Utility of Stylistics}

In spite of a clearly defined scope of activity stylistics, its methods and object of study, there remain a number of sagas about contemporary stylistics because of the misunderstanding of scope and significance of language analysis for stylistic orientation. This is an erroneous presumption, because the linguistic analysis of language patterns and components is not for its own sake or futile activity, but a very important means for a higher purpose (that is, a basis for building a systematic objective verifiable literary evaluation). For instance, the afore-analyzed phrase 'a grief ago' and the sentence "I kissed thee ere I killed thee" incorporate much analysis and counting of the parts of speech and their functions. However, the issue does not stop there; it sets the stage for further semantic and artistic evaluation. The ability of an analyst to unearth stylistic features generally depends on his linguistic and literary awareness. As affirmed by Simpson (2004), the "method of stylistics is full gamut of the system of language that makes all aspects of a writer's craft relevant in stylistic analysis. It goes from counting linguistic items to the main target which is evaluation of the text". Thus, the linguistic analysis at the level of graphology, phonology, morphology, and syntax were verifiable, objective, formal evidences supporting, corresponding and correlating the stylistician's qualitative and artistic critical verdict, otherwise, there will be no difference between stylistic analysis and literary criticism.

According to Fairclough (2001), "Discourse constitutes the social. Three dimensions of the social are distinguished - knowledge, social relations, and social identity - and these correspond respectively to three major functions of language: Expressive, informative and directive functions. Discourse is shaped by relations of power and invested ideologies." Discourse, according to Harris (1951), who first used the term, is a sequence of the utterances. He observed that:

"Stretches longer than one utterance are not usually considered in current descriptive linguistics.[...] the linguist usually considers the interrelations of elements only within one utterance at a time. This yields a possible description of the material, since the interrelations of elements within each utterance (or utterance type) are worked out, and any longer discourse is describable as succession of utterances, i.e. a succession of elements having the stated interrelations. This restriction means that nothing is generally said about the interrelations among whole utterances within a sequence."

Grenoble (2000), explaining Harris's definition of discourse, stated that:

"Harris interestingly enough ruled out the kind of study which discourse analysis aims to do. He is of the view that linguistic research focuses on the elements within an utterance; discourse can be considered as a sequence of utterance. Harris argues that the study of the interrelations between utterances within a discourse; the scope of a discourse analysis required much more information than the theoretical apparatus of that time could handle. While this held true for 1950s and 1960s, roughly, but 1970s saw an emerging body of different approaches including pragmatics, conversation analysis, textual linguistics, and relevance theory."

According to Fairclough (2001), DA being a relative social phenomenon, solely depends on a wide range of disciplines, such as sociology, anthropology, cognitive and social psychology, for knowledge and methodologies and it is difficult to draw a clear line of demarcation between certain linguistic fields, such as anthropological linguistics, psycholinguistic, discourse analysis and cognitive linguistics, as the approaches to 'study of language in use' are borrowed from these subfields. Additionally, most of the times the findings are independently 
supported by the fresh evidences. DA, in turn, is composed of a wide range of sub-disciplines, such as pragmatics, conversational analysis, speech act theory and ethnography of speaking. The discipline studies language used in the context, so its subject matter is language as a whole, either written or spoken, in terms of transcriptions, larger texts, audio or video recordings. This provides an opportunity to the analyst to work with language rather than a single sentence. Pragmatics as a general term, according to Grenoble (2000), can be understood in at least as many ways as DA; some linguists equate the two terms. In its narrow sense, it refers to linguistic theory that has been directly influenced by the philosophy of language. The present paper is concerned with the approaches, either similar or different, used by stylistics and DA to analyze different literary genres.

\subsubsection{Differences Between DA, Stylistic Analysis and Literary Criticism}

The major difference among DA, stylistic analysis, and literary criticism was previously demonstrated in the above discussions. Hereunder, the distinction between discourse and the rest of topics understudy would be clarified. Both stylistics and DA are concerned with linguistic analysis of a text. However, discourse is concerned with linguistic analysis of a pattern above sentence and language of a text in a context. Contrarily, stylistics focuses on the linguistic analysis of the components of a sentence, that is, phonology, morphology, phrase, clause, and the sentence which is the highest component under the investigation of the stylistics. In DA, the interpretation of stretch of language takes into consideration issues such as speech-act theory.

A speech act in linguistics and the philosophy of language is an utterance has performative function in language and communication. The speech-act philosopher, Grice (1975) coined the term 'implicature' to explain how listeners are able to identify the illocutionary force of an utterance that lacks an explicit indicator of its illocutionary intention. For instance, "Can you pass the salt?" can be used by the speaker, and correctly understood by the hearer, as a polite form of request although it is in the syntactical form of a question.

According to Bach (1994, pp. 124-162):

"Almost any speech act is really the performance of several acts at once, distinguished by different aspects of the speaker's intention: there is the act of saying something, what one does in saying it, such as requesting or promising, and how one is trying to affect one's audience".

The contemporary use of the term goes back to J. L. Austin's development of performative utterances and his theory of locutionary, illocutionary, and perlocutionary acts. These three different aspects of an utterance can occur simultaneously. Locutionary acts are the mere act of producing some linguistic sounds or marks with a certain meaning and reference. It is the simple act of a speaker saying something. Illocutionary acts, then, carry a directive for the audience. It might be a promise, an order, an apology, or an expression of thanks. Conversely, perlocutionary acts bring about a consequence to the audience if something is not done.

Moreover, felicity conditions in pragmatics and speech-act theory, were introduced by Austin (1962) and further developed by American philosopher J. R. Searle. Felicity conditions refer to the conditions that must be in place and the criteria that must be satisfied for a speech act to achieve its purpose; these are also called presuppositions. Grice $(1975,1989)$ proposed that users of a language share a set of implicit expectations which he calls the 'communicative presumption'-for example, that an utterance is intended by a speaker to be true, clear, and above all relevant. If an utterance seems purposely to violate these expectations, then sense is sought of it by transferring it to a context in which it is clearly appropriate. These felicity conditions are as follows: an essential condition (whether a speaker intends that an utterance be acted upon by the addressee); a sincerity condition (whether the speech act is being performed seriously and sincerely), and; a preparatory condition (whether the authority of the speaker and the circumstances of the speech act are appropriate to its being performed successfully).

Important maxims called Grice's maxims have to be observed in successful discourse or proper communication. These are inclusive of the maxim of quality, which is concerned with the truthfulness of any statement, maxim of quantity which is concerned with concise and adequate information, maxim of relation which is concerned with the relevance of the statement, and finally maxim of manner which is concerned with being perspicuous (lucid/clearly expressed/easily understood). These are required in order to fulfil a discourse. DA is concerned with analyzing a literary work in terms of speech act theory, performative utterances and the theory of locutionary, illocutionary and perlocutionary acts, co-operative principles and felicity conditions. The meaning is interpreted according to the intention of the speaker listener and the social context.

The collective assumptions that assist to attempt utterances significantly and intelligible serve for making a maintained discourse based on a comprehensive development of Grice's analysis rather than a just juxtaposition of independent sentences. There are several assumptions that show that the speaker is using language in an 
approach that is purposive, intentional, and based on cultural and linguistic conventions. Secondly, the listener shares an extensive body of non-linguistic experience and knowledge with the speaker. Thirdly, the specific situation differs from the shared knowledge of complex approaches in which the meaning of a location differs with respect to the type of discourse in which it is present. DA is included in the investigation area with some stylistics proponents.

The issue of speech act theory is a very important distinguishing element between stylistics analysis and DA. Stylistics could not analyze a text in term of speech act because a literary text lacks the three characteristics of a discourse; namely, locutionary, illocutionary, and perlocutionary acts. This is because they are not obvious in a literary context such as a poem. Moreover, neither the intention of the writer nor the feedback from the listener is available and explicitly affirmed. Similarly, the cooperative principles are obviously violated in a poem. There is no control over the quality, quantity, relevance, and manner of speech. The same thing could be stated about issue of felicity conditions because it is not clear whether a speaker intends that an utterance be acted upon by the addressee in a poem story or a novel, or the sincere, that is, whether the speech act is being performed seriously and sincerely or whether the authority of the speaker and the circumstances of the speech act are appropriate to its being performed successfully. These issues are not in the scope of stylistic analysis. It is restricted to discourse analysis. Anyhow, since the late 1970s, many attempts have progressively made to apply DA to the investigation of the discourse in novels and dramas. A main purpose is to elucidate how the characters embodied in a literary work, and also the readers of that work, are continuously able to deduce meanings that are not stated or specified in a conversational interchange. The claim is that such inferences are 'rule-governed', in that they depend on sets of assumptions shared by users and interpreters of discourse that come into play to establish meanings. Furthermore, these meanings vary systematically in accordance with whether the rule-guided expectations are fulfilled or intentionally violated. Such explorations of conversational discourse in literature often extend to the re-analysis of point of view and other traditional topics in the criticism of literary narratives.

In comparing DA and literary criticism, it is obvious that there is no any confusion about the clear demarcation between the two, since the latter is a subjective and impressionistic view of a critic which is not based on the formal aspects of a text; consequently, linguistics is very obviously distinctive from the boundaries of critics. Of course, the critic deciphers the text made of language, but his criticism is the end product of his feelings and his response to the images, ideas and the like.

\section{Conclusion}

The present study has discussed the relationships among linguistic analysis, literary criticism, discourse analysis and stylistics analysis, with a special focus on demonstrating the differences between linguistics, stylistics and literary criticism. This helped in demonstrating the usage of language in literary texts by relating it to its artistic function. The results have clearly shown that linguistics, stylistics, DA and literary criticism analyze literary and non-literary texts and are strongly inter-connected. It has showed that style entails a variety of influences, which might be a confluence of references from the wide of world of scholarship. Furthermore, style and meaning come about in large part because of the linguistic choices that writers and speakers make. Grammatical constructions and phonetic patterns include important aspects of meaning and effect that were detected in a text by paying close attention to the words. This helped in comparing different relationships, which could have been made in the same context. Stylistics is the deconstruction of the language in terms of its structure; while, literary criticism focuses on the ideas, philosophy, and thoughts inherent in the body of a text.

The results have depicted that the literary criticism approach to literature should be clearly demarcated from stylistic textual analysis of a literary text. Stylistic analysis embarks on the analysis of the components of the literary texts and examines them linguistically to discover the distinctive characteristics that make them highly noticeable and contributing for interpreting the literary text. Stylistics is a linguistic evaluation while literary criticism finds the text as the source of all ideas. The practical implications of this study include increase in the competence of stylistician in analyzing language structures and training language study. This approach towards literary criticism helps in releasing literary criticism from subjective and impressionistic judgment and deal with it scientifically. The stylistic analysis of literary texts aims to demonstrate how linguistic stylistic can be of help in understanding literature works along with its interpretation. Therefore, the interrelationship among these three previously stated disciplines is obvious.

The approach to stylistic analysis is linguistic to arrive at the interpretation and artistic effect that is the immediate concern of the literary criticism. Linguists now make critical analysis that contribute directly to literary interpretation and evaluation. Conversely, DA attempts to analyze literature and non-literary discourse or text in terms of co-operative principles, with derived maxims, speech acts, and conversational analysis. However, 
one could not analyze literary text from the point of view of speech acts in stylistic analysis in which explicit performative utterances are infrequent. DA faces the same problem with the utterances in novels and poetry, in which there is no explicit performative significance. The study of discourse is the study of any aspect of language in use as it is impossible to understand the linguistic items used in discourse without a context.

\section{References}

Aslam, S., Aslam, B., Mukhtar, P., \& Sarfaraz, A. (2014). Stylistics analysis of the poem Bereft by Robert Frost. European Journal of Research and Reflection in Arts and Humanities, 2(1), 1-5. https://doi.org/10.18187/pjsor.v8i2.237

Austin, J. L. (1962). How to Do Things with Words (p. 13). Cambridge, Mass: Harvard. https://doi.org/10.1093/acprof:oso/9780198245537.001.0001

Bach, K. (1994). Conversational implicature. Mind \& language, 9(2), 124-162. https://doi.org/10.1111/j.1468-0017.1994.tb00220.x

Birch, D. (1995). Context and Language: A Functional Linguistic Theory of Register. London, New York: Pinter.

Birch, D. (2005). Language, literature and critical practice: Ways of analyzing text. Routledge. https://doi.org/10.4324/9780203976845

Burke, M. (2015). Unpacking and evaluating properties in conceptual metaphor domain mapping: Cognitive stylistics as a language learning tool. In T. Masayuki, S. Yoshifumi \& W. Katie (Eds.), Literature and Language Learning in the EFL Classroom (pp. 75-93). London: Palgrave Macmillan. https://doi.org/10.1057/9781137443663_6

Cain, B. E. (2018). British and American New Criticism. A Companion to Literary Theory, 11. https://doi.org/10.1002/9781118958933.ch1

Colleman, T., Röthlisberger, M., \& Zehentner, E. (2017, September). Ditransitive constructions in Germanic Languages: Diachronic and synchronic aspects. In Book of Abstracts (p. 440). https://doi.org/10.1515/zaa-2011-0408

Crystal, D., \& Davy, D. (2016). Investigating English style. Routledge. https://doi.org/10.2307/412181

Derrida, J. (2016). Of grammatology. JHU Press.

Downes, W. (1998). Language and society. Cambridge University Press. https://doi.org/10.1017/CBO9781139163781

Fairclough, N. (2001). Language and power. Pearson Education.

Ferguson, F., \& Mackay, E. (2018). Introduction: Thinking about the Chicago School of Criticism. Modern Philology, 115(4), 425-431. https://doi.org/10.1086/696373

Gee, J. P. (2004). An introduction to discourse analysis: Theory and method. Routledge. https://doi.org/10.4324/9780203019887

Grenoble, L. A. (2000). Discourse analysis. SLIN2K position paper, Dartmouth college, USA.

Grice, H. P. (1975). Logic and conversation. In P. Cole \& J. Morgan (Eds.), Syntax and semantics (vol. 3). Speech acts.

Halliday, M. A. K., \& Jonathan, W. (2006). On Language and Linguistics (p. vii.). Continuum International Publishing Group.

Harris, Z. S. (1951). Methods in structural linguistics. https://doi.org/10.2307/409684

Hult, F. M. (2017). Discursive approaches to policy. In S. E. F. Wortham, D. Kim \& S. May (Eds.), Discourse and education (pp. 111-121). New York: Springer. https://doi.org/10.1007/978-3-319-02243-7_22

Krishnamurthy, S. (2010). The chutnification of English: An examination of the lexis of Salman Rushdie's Midnight's Children.

Lewis, C. S. (1992). An Experiment in Criticism. Cambridge: Cambridge UP.

Montoro, R. (2014). Feminist stylistics. The Routledge Handbook of Stylistics (pp. 346-361). Abingdon and New York, NY: Routledge. https://doi.org/10.4324/9781315795331.ch21

Naciscione, A. (2017). Stylistic use of phraseological units in discourse. John Benjamins Publishing Company. https://doi.org/10.1075/z.159 
Rosenblatt, L. (1938). Literature as Exploration. New York: Noble and Noble, Publishers.

Short, M. (2016). Exploring the language of poems, plays and prose. Routledge. https://doi.org/10.2307/3736116

Short, M. H., \& Leech, G. N. (2013). Style in fiction: A linguistic introduction to English fictional prose. Routledge. https://doi.org/10.4324/9781315835525

Simpson, P. (2004). Stylistics: A resource book for students. Psychology Press. https://doi.org/10.4324/9780203496589

Van Dijk, T. A. (2015). 22 Critical Discourse Analysis. The handbook of discourse analysis, 466. https://doi.org/10.1002/9781118584194.ch22

Wales, K., (2011). A dictionary of stylistics (3rd ed.). Harlow: Longman. https://doi.org/10.4324/9781315833507

Wimsatt, W. K., \& Beardsley, M. (2014). The Intentional Fallacy (1946) 3.4. The Lyric Theory Reader: A Critical Anthology, 201. Retrieved from http://www.gbv.de/dms/goettingen/747053383.pdf

\section{Copyrights}

Copyright for this article is retained by the author(s), with first publication rights granted to the journal.

This is an open-access article distributed under the terms and conditions of the Creative Commons Attribution license (http://creativecommons.org/licenses/by/4.0/). 